\title{
Hepatoprotective effect of licorice, the root of Glycyrrhiza uralensis Fischer, in alcohol- induced fatty liver disease
}

\author{
Jae-Chul Jung ${ }^{1 \dagger}$, Yun-Hee Lee ${ }^{2 \dagger}$, Sou Hyun Kim³ ${ }^{3}$ Keuk-Jun Kim', Kyung-Mi Kim', Seikwan Oh${ }^{5}$ \\ and Young-Suk Jung ${ }^{3^{*}}$
}

\begin{abstract}
Background: Our previous study suggested that licorice has anti-inflammatory activity in lipopolysaccharidestimulated microglial cells and anti-oxidative activity in tert-butyl hydroperoxide-induced oxidative liver damage. In this study, we evaluated the effect of licorice on chronic alcohol-induced fatty liver injury mediated by inflammation and oxidative stress.

Methods: Raw licorice was extracted, and quantitative and qualitative analysis of its components was performed by using LC-MS/MS. Mice were fed a liquid alcohol diet with or without licorice for 4 weeks.

Results: We have standardized $70 \%$ fermented ethanol extracted licorice and confirmed by LC-MS/MS as glycyrrhizic acid (GA), $15.77 \pm 0.34 \mu \mathrm{g} / \mathrm{mg}$; liquiritin (LQ), $14.55 \pm 0.42 \mu \mathrm{g} / \mathrm{mg}$; and liquiritigenin (LG), $1.34 \pm 0.02 \mu \mathrm{g} / \mathrm{mg}$, respectively. Alcohol consumption increased serum alanine aminotransferase and aspartate aminotransferase activities and the levels of triglycerides and tumor necrosis factor (TNF)-a. Lipid accumulation in the liver was also markedly induced, whereas the glutathione level was reduced. All these alcohol-induced changes were effectively inhibited by licorice treatment. In particular, the hepatic glutathione level was restored and alcohol-induced TNF-a production was significantly inhibited by licorice.
\end{abstract}

Conclusion: Taken together, our data suggests that protective effect of licorice against alcohol-induced liver injury may be attributed to its anti-inflammatory activity and enhancement of antioxidant defense.

Keywords: Licorice, Alcohol-induced liver injury, Glutathione, TNF-a

\section{Background}

Licorice is the root of Glycyrriza uralensis Fischer, Glycyrrhiza glabra Linné or Glycyrrhiza inflata Batalin (Fabaceae), which has been used as traditional medicine since ancient times. In particular, licorice was used as a medical raw material for multiple purposes such as antidote, antitussive expectorant, relaxant, to relieve pain that occurs because of a sudden nervous breakdown of muscle or tissue, to reduce weight gain, to increase white blood cell count, and also because of its diuretic and anti-inflammatory effects [1]. Although licorice has been

\footnotetext{
* Correspondence: youngjung@pusan.ac.kr

${ }^{\dagger}$ Equal contributors

${ }^{3}$ College of Pharmacy, Pusan National University, Busan 609-735, Republic of Korea

Full list of author information is available at the end of the article
}

used in both Eastern and Western medicine to treat a wide variety of diseases from common cold to liver disease, more scientific evidence is needed to prove its potential preventive and therapeutic benefits. The biologically active components of licorice are liquiritins (LQ), liquiritigenin (LG), glycyrrhizic acids (GAs), and flavones (Fig. 1). Various biological effects of these compounds and pharmacokinetics of glycyrrhizic acid have been reported [2-4]. In addition, studies have been performed to analyze and characterize primary and secondary metabolites of licorice $[5,6]$.

Accumulating lines of evidence show that licorice has anti-inflammatory, anticancer, antioxidant, and antimicrobial effects [1, 4, 7-9]. In particular, recent studies on hepatoprotective effects of licorice suggest that it can reduce liver injury by enhancing antioxidant and anti- 


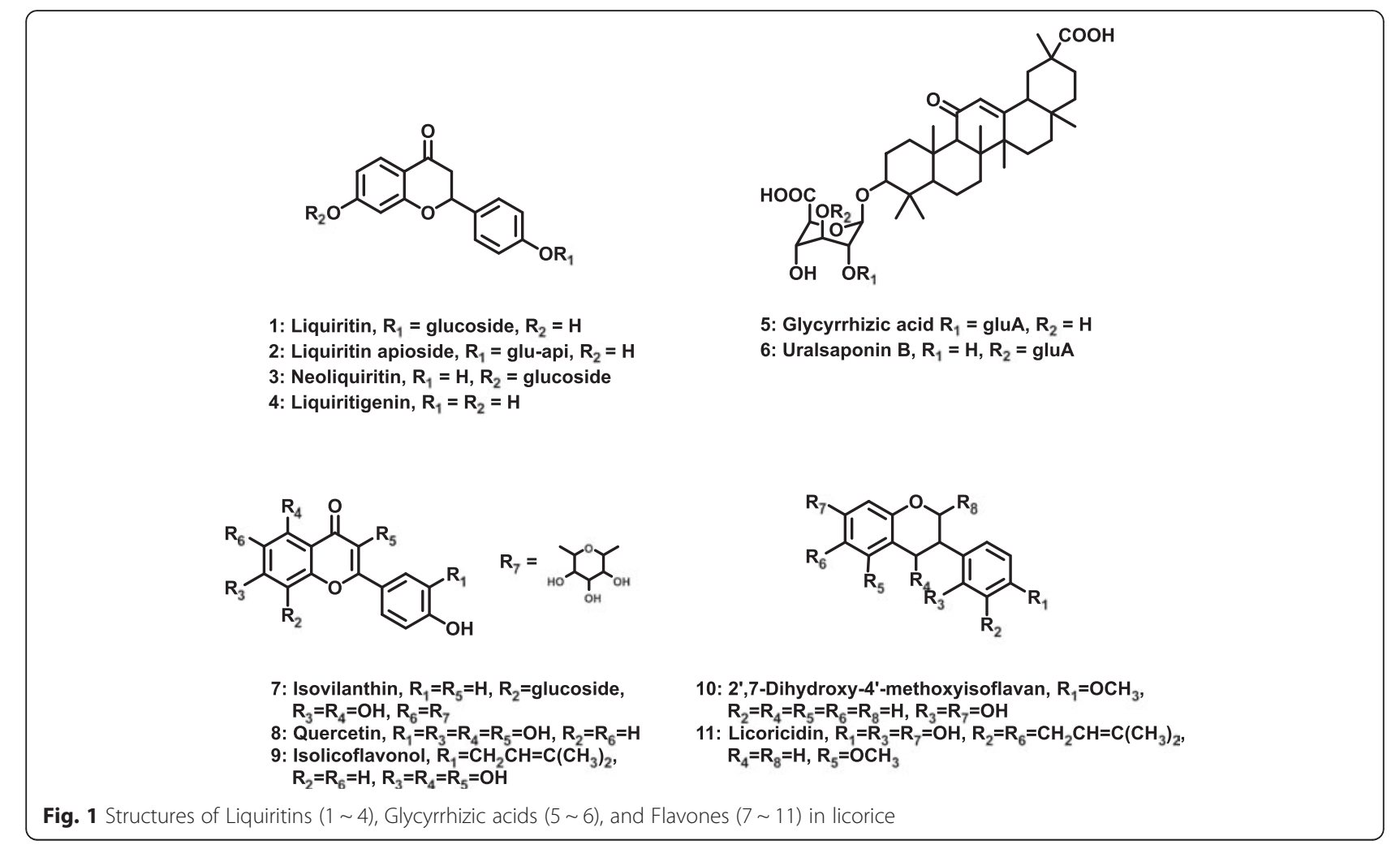

inflammatory capacity $[7,10]$. Administration of licorice extract prevented $\mathrm{CCl}_{4}$-induced hepatotoxicity by increasing antioxidant enzyme activity and decreasing TNF- $\alpha$ production [11]. Jung et al. [12] investigated the hepatoprotective effects of $18 \beta$-glycyrrhetinic acid, one of the active compounds in licorice, in a $\mathrm{CCl}_{4}$-induced liver injury model. Treatment with $18 \beta$-glycyrrhetinic acid inhibited the increase in serum alanine aminotransferase (ALT) and aspartate aminotransferase (AST) activities and hepatic lipid peroxidation in a dosedependent manner. In addition, 18ß-glycyrrhetinic acid significantly protected against glutathione (GSH) depletion. Although these studies show a promising effect of licorice in preventing liver injury, their limitation was that the chemically induced acute hepatotoxicity model used was not very relevant to clinical situations.

Alcohol abuse causes a range of acute and chronic health problems worldwide, which lead to morbidity and mortality. Depending on overall alcohol consumption and drinking patterns, chronic exposure to alcohol is harmful to the central nervous system and many organs, including the liver. Among alcohol-induced liver diseases, fatty liver is the most common histopathologic condition in drinkers. Although alcohol-induced fatty liver is widely considered to be benign and to have a very low risk of progression, clinical studies have provided evidence that it is an important pathogenic factor in the development of liver disease [13-15]. Specifically, the authors suggested that both oxidative stress and inflammation as second hits are critical factors in the pathological progression from simple fat accumulation to liver disease. Recently, we reported that licorice extract had an anti-inflammatory effect in lipopolysaccharide-stimulated microglial cells and acted as an antioxidant in a tert-butyl hydroperoxide-induced oxidative liver injury model [16]. Therefore, it was of interest to examine the effects of licorice on chronic alcohol-induced fatty liver, which is more relevant to clinical situations. In this study, we examined the preventive effect of licorice in alcoholic fatty liver by administering its extract to mice exposed to alcohol for 4 weeks.

\section{Methods}

\section{Extraction}

Glycyrrhiza uralensis Fisher (Fabaceae) was cultivated in Jecheon, Chungbuk Province, Korea. The raw material has been provided by the Korea Licorice Farming Association in 2013 and its extraction was produced by Tecos Co., Ltd (Chuncheon, Korea). Prof. Min Hye Yang of the Pusan National University identified plant material and a voucher specimen (PNU-0020) has been deposited in the Medicinal Herb Garden, Pusan National University (Busan, Korea). The analysis of biological component and microbiological test were confirmed by Novarex Co., Ltd (Ochang, Korea). All other chemicals were purchased from Sigma Chemical Co. (St. Louis, MO, 
USA) and Wako Pure Chemical Industries (Osaka, Japan). The raw material of licorice (the root of Glycyrrhiza uralensis Fisher, $400 \mathrm{~kg}$ ) was extracted for $3 \mathrm{~h}$ using a reflux circulation of $70 \%$ aqueous ethanol $(2800 \mathrm{~L})$. The extracts was cooled at $30 \sim 35{ }^{\circ} \mathrm{C}$ and filtered using $75 \mu \mathrm{m}$ cartridge and then the residue of raw materials was removed through subject of a centrifuge. The residue was concentrated in vacuo under reduced pressure $\left(10 \mathrm{~atm}, 55 \sim 58{ }^{\circ} \mathrm{C}\right)$ to reach $10 \sim 20$ brix materials $(52 \sim 64 \mathrm{~kg})$. The residue was blended with dextrin and sterilized at $95{ }^{\circ} \mathrm{C}$ for $30 \mathrm{~min}$ and then it was spray-dried (liquid temperature: $75 \sim 80{ }^{\circ} \mathrm{C}$, the blowing temperature of $180{ }^{\circ} \mathrm{C}$, atomizer $18,000 \mathrm{rpm}$ ) to provide a licorice extract powder (90 kg, $11.3 \%$ ). To establish bulk scale production of licorice extracts, we confirmed manufacturing process based on experimental pilot condition using Jecheon domestic licorice in Korea (Fig. 2).

\section{Analysis of licorice extract}

To confirm two index components such as triterpenoid saponin series GA and flavonoids LQ, we performed quantitative and qualitative analysis through HPLC and HPLC-MS/MS based on United States Pharmacopoeia and Korean Pharmacopeia as standard analytical methods (Fig. 3).

\section{Analytical condition of LC-MS/MS}

We used digoxin as internal standard in order to quantitative analysis of major components GA, LQ, and LG of licorice extract. In addition, we performed material separation for each component of the material using LUNA $\mathrm{C}_{18}$ column $(2.0 \times 150 \mathrm{~mm}, 5 \mu \mathrm{m})$. Solvent A was water with $1.0 \%$ acetic acid and solvent B was acetonitrile with $1.0 \%$ acetic acid. The gradients of solvents were as followings: $0 \mathrm{~min}, 10 \% \mathrm{~B} ; 1 \mathrm{~min}, 10 \% \mathrm{~B} ; 6.5 \mathrm{~min}, 90 \% \mathrm{~B}$; 8 min, 90 \% B; 8.5 min, 10 \% B; 15 min, 10 \% B. Samples were dissolved in $50 \%$ acetonitrile and the injection volume of each sample was $5 \mu$ l. Detailed condition for LCMS/MS analysis is in the Table 1.

\section{Animals and treatments}

Male C57BL/6 mice were purchased from Orient Bio (Sungnam, Korea). The use of animals was in compliance with the guidelines established and approved by the Institutional Animal Care and Use Committee in Pusan National University (PNU-2014-0568). Animals were acclimated to temperature $\left(22 \pm 2{ }^{\circ} \mathrm{C}\right)$ and humidity $(55 \pm$ $5 \%)$ controlled rooms with a 12-h light/dark cycle for 1 week prior to use. The diets were purchased from Dyets Inc. (Bethlehem, PA, USA). Mice were fed a Lieber-DeCarli liquid diet with or without ethanol for 4 week. For the control liquid diet, $35 \%$ of energy was derived from fat, $18 \%$ from protein, and $47 \%$ from carbohydrates; the liquid ethanol diet contained $35 \%$ of energy from fat, $18 \%$ from protein, $11 \%$ from carbohydrates, and $36 \%$ from ethanol.

\section{Serum biochemistry and histopathologic evaluation}

Serum levels of alanine aminotransferase (ALT), aspartate aminotransferase (AST), total serum triglyceride (TG) were measured using Automated Chemistry Analyzer (Prestige 24I; Tokyo Boeki Medical System, Tokyo, Japan). For histopathologic evaluation, a cross section of the left lateral lobe of the liver was sliced at $10 \mu \mathrm{m}$, immersed in propylene glycol for $5 \mathrm{~min}$, and

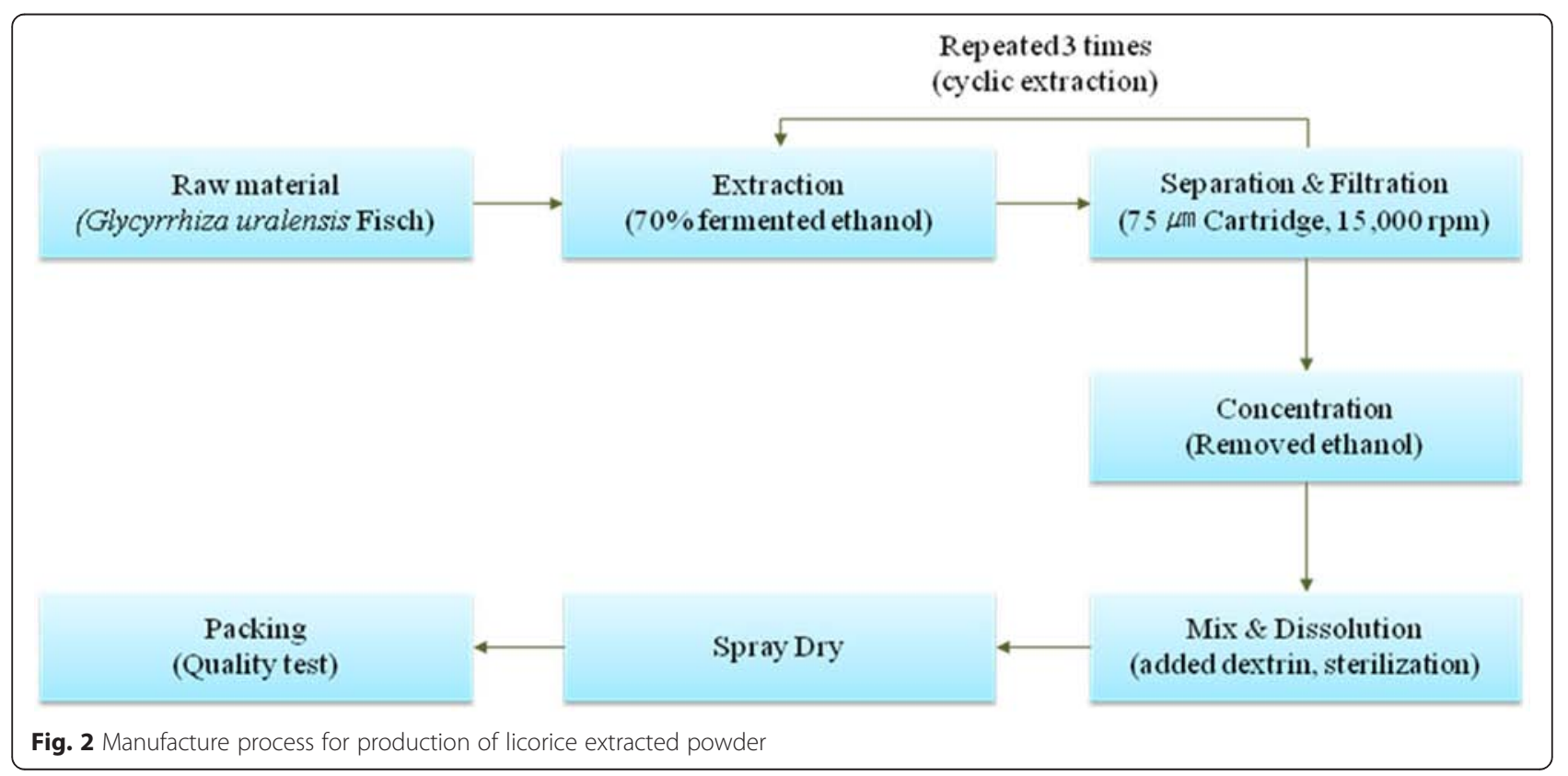



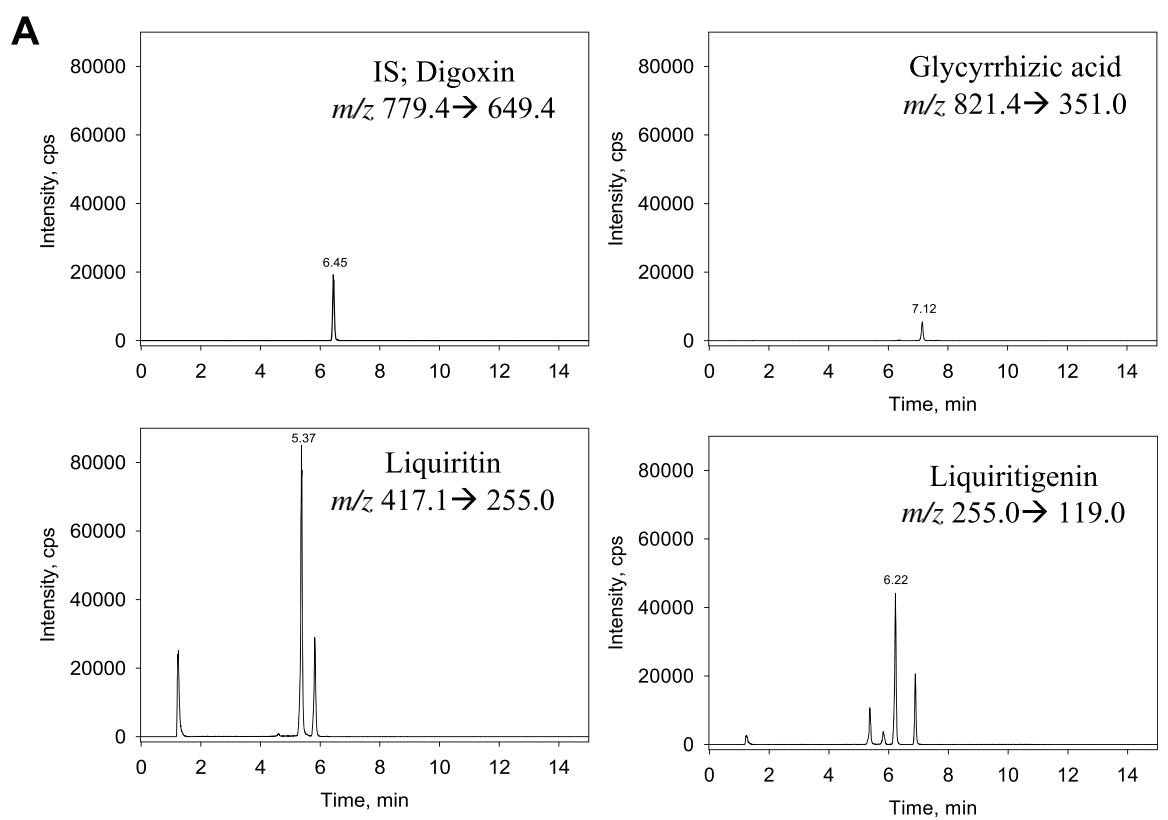

B



Fig. 3 LC-MS/MS spectrum of standard (a) and licorice extract (b)

stained with Oil red $\mathrm{O}$ for $7 \mathrm{~min}$. After rinsing with $85 \%$ propylene glycol and distilled water, the sections were counterstained with hematoxylin for $2 \mathrm{~min}$ before microscopic examination.

\section{Measurement of serum TNF-a}

The levels of serum TNF- $\alpha$ were determined by enzymelinked immunosorbent assay using a commercially available kit (R\&D Systems, Minneapolis, MN) according to the manufacturer's instruction.

\section{Determination of hepatic triglyceride contents}

Total lipids of the liver were extracted from homogenate prepared from $100 \mathrm{mg}$ of mouse liver using the mixture of chloroform/methanol (2:1, v/v). Triglycerides in total lipid were determined enzymatically using a commercially available enzymatic kit (Sigma Chemical Co.) according to the manufacturer's protocol.

\section{Measurement of hepatic glutathione (GSH)}

Liver was homogenized in a four-fold volume of ice-cold $1 \mathrm{M}$ perchloric acid. After the denatured protein was removed by centrifugation at $10,000 \mathrm{~g}$ for $10 \mathrm{~min}$, the supernatant was assayed for the total GSH concentration using a HPLC separation/fluorometric detection method [17].

\section{Real time RT-PCR}

Total RNA was purified from liver tissue using the RNeasy kit (Qiagen, Valencia, CA, USA). cDNA synthesis was accomplished with iScript ${ }^{\mathrm{m} w}$ cDNA Synthesis system (Bio-Rad, Hercules, CA, USA). Real time RT-PCR was performed using Thunderbird SYBR qPCR mix 
Table 1 Condition for LC-MS/MS analysis of Licorice extracts

\begin{tabular}{ll}
\hline A. & \\
Column & Luna C 18 RP column $(2.0 \times 150 \mathrm{~mm}, 5 \mu \mathrm{m})$ \\
Flow rate & $0.3 \mathrm{~mL} / \mathrm{min}$ \\
Injection volume & $5 \mu \mathrm{L}$ \\
Column temperature & $40^{\circ} \mathrm{C}$ \\
Autosampler temperature & $4{ }^{\circ} \mathrm{C}$ \\
B. & \\
Mass condition & \\
lon source & Turbo spray (Negative) \\
Curtain Gas & $30 \mathrm{psi}$ \\
Collision Gas & $\mathrm{N}_{2}$ (Medium) \\
lonspray Voltage & $-4.0 \mathrm{kV}$ \\
Source temperature & $400{ }^{\circ} \mathrm{C}$ \\
Gas 1 & $40 \mathrm{psi}$ \\
Gas 2 & $50 \mathrm{psi}$
\end{tabular}

(Toyobo Co., Ltd., Osaka, Japan) according to the manufacturer's protocol. Relative values of gene expression were normalized to $18 \mathrm{~S}$ ribosomal RNA. Primer sequences and full name of the genes are provided in Additional file 1: Table S1.

\section{Statistical analysis}

All results expressed as mean \pm s.d. were analyzed by one-way analysis of variance (ANOVA) followed by Newman-Keuls multiple range test (parametric). The acceptable level of significance was established at $P<0.05$.

\section{Results}

We analyzed licorice extract composition based on testing condition using a Shiseido HPLC system coupled to an AB Sciex electrospray-ionization (ESI) mass-spectrometer (Table 2). For quantitative LC-MS/MS analysis of each component, we established optimal conditions for the precursor ion and product ion by adjusting collision energy, cone voltage, and cone temperature of the ion source (Table 1). The instrument was operated in the multiplereaction-monitoring (MRM) mode.
We prepared the calibration curves for GA, LQ, and LG according to the concentration-dependent ESI method in LC-MS/MS analysis. We found that the correlation coefficient $\left(r^{2}\right)$ values were 0.9999, 0.9997, and 0.9998 , respectively, which showed good linearity of the calibration curves (Table 2). The limit of detection (LOD) was $4.29 \mathrm{ng} / \mathrm{mL}, 1.27 \mathrm{ng} / \mathrm{mL}$, and $0.54 \mathrm{ng} / \mathrm{mL}$, whereas the limit of quantitation (LOQ) was $13.99 \mathrm{ng} /$ $\mathrm{mL}, 3.86 \mathrm{ng} / \mathrm{mL}$, and $1.64 \mathrm{ng} / \mathrm{mL}$, respectively.

We performed quantitative analysis of GA, LQ, and LG. The MRM conditions were $\mathrm{m} / \mathrm{z} 821.4$ (precursor ion) $\rightarrow$ 351.0 (product ion) for GA, $\mathrm{m} / \mathrm{z} 417.1$ (precursor ion) $\rightarrow$ 255.0 (product ion) for $\mathrm{LQ}$, and $\mathrm{m} / \mathrm{z} 255.0$ (precursor ion) $\rightarrow 119.0$ (product ion) for LG. We set up the amount of digoxin as internal standard at $\mathrm{m} / \mathrm{z} 779.4$ (precursor ion) $\rightarrow 649.4$ (product ion). For quantitative analysis, we used the calibration curves to calculate the ratios of compounds in the analyzed material to respective standards. We diluted licorice extract $1 / 20$ to ensure that the concentrations of its components are within the quantitative ranges of the calibration curves, and then multiplied the obtained concentrations by 20 (the dilution factor). The results of quantitation of the licorice extract components were as follows: GA, $15.77 \pm 0.34 \mu \mathrm{g} / \mathrm{mg} ; \mathrm{LQ}, 14.55 \pm$ $0.42 \mu \mathrm{g} / \mathrm{mg}$; and LG, $1.34 \pm 0.02 \mu \mathrm{g} / \mathrm{mg}$ (Table 3).

To test the effect of licorice on alcohol-induced fatty liver, a dose-dependence study was performed in mice fed a standard Lieber-DeCarli liquid diet supplemented with ethanol for 4 weeks (Fig. 4). Different dosage of licorice ranging from $25 \mathrm{mg} / \mathrm{kg}$ body weight to $200 \mathrm{mg} / \mathrm{kg}$ body weight was orally administered every day from the beginning of the liquid diet. At the end of the treatment period, lipid accumulation in the liver was evaluated by Oil Red-O staining (Fig. 4a). Serum ALT and AST activities were also determined (Fig. 4b and c). The dose of 25 to $50 \mathrm{mg} / \mathrm{kg}$ body weight was not effective, but treatment with doses exceeding $100 \mathrm{mg} / \mathrm{kg}$ significantly reversed hepatic lipid accumulation and serum ALT, AST activities (Fig. 4).

We compared the effect of licorice $(100 \mathrm{mg} / \mathrm{kg}$ body weight) on alcoholic fatty liver with that of silymarin (100 mg/kg body weight; Sigma Chemical Co., Cat S0292), which is a well-known compound that alleviates alcohol-induced liver injury. Using staining with Oil Red-O and evaluation of hepatic triglyceride, we found

Table 2 Linearities, regression equation, correlation coefficients, limit of detection (LOD), and limit of quantitation (LOQ) for glycryrrhizic acid (GA), liquiritin (LQ) and liquiritigenin (LG)

\begin{tabular}{lllccc}
\hline Compounds & Linear range $(\mathrm{ng} / \mathrm{ml})$ & Regression equation & Correlation coefficient & $\mathrm{LOD}^{\mathrm{b}}\left(\mathrm{ng} / \mathrm{ml}^{\mathrm{a}}\right)$ & $\mathrm{LOQ}^{\mathrm{c}}(\mathrm{ng} / \mathrm{ml})$ \\
\hline Glycyrrhizic acid (GA) & $12.5-5000$ & $\mathrm{Y}=0.0004 \mathrm{x}-0.0055$ & 0.9999 & 4.62 & 13.99 \\
Liquiritin (LQ) & $12.5-1000$ & $\mathrm{Y}=0.0059 x+0.0451$ & 0.9997 & 1.27 & 3.86 \\
Liquiritigenin (LG) & $12.5-500$ & $\mathrm{Y}=0.0289 \mathrm{x}+0.1574$ & 0.9998 & 0.54 & 1.64 \\
\hline
\end{tabular}

${ }^{\mathrm{a}} \mathrm{y}$ : Analyte area / IS area; $\mathrm{x}$ : concentration $(\mathrm{ng} / \mathrm{mL})$ of compounds

${ }^{\mathrm{b}} \mathrm{LOD}=3.3 \times \delta / \mathrm{S}(\delta$; standard deviation, $\mathrm{S}$; slope of the calibration curve)

${ }^{c} \mathrm{LOQ}=10 \times \delta / S(\delta ;$ standard deviation, S; slope of the calibration curve) 
Table 3 Analytical LC-MS/MS data of licorice extracts

\begin{tabular}{|c|c|c|c|c|c|c|c|c|}
\hline Compounds & & Peak area & IS area & Analytes/IS ratio & Calculation & $\mu \mathrm{g} / \mathrm{mg}$ & Ave. & S.D. \\
\hline \multirow[t]{3}{*}{ Glycyrrhizic Acid (GA) } & 1/20 dil.1 & 23,132 & 74,555 & 0.31 & 789.42 & 15.79 & 15.77 & 0.34 \\
\hline & 1/20 dil.2 & 23,226 & 73,402 & 0.32 & 804.80 & 16.10 & & \\
\hline & 1/20 dil.3 & 23,016 & 75,956 & 0.30 & 771.29 & 15.43 & & \\
\hline \multirow[t]{3}{*}{ Liquiritin (LQ) } & 1/20 dil.1 & 316,205 & 74,555 & 4.24 & 711.21 & 14.22 & 14.55 & 0.42 \\
\hline & 1/20 dil.2 & 328,810 & 73,402 & 4.48 & 751.61 & 15.03 & & \\
\hline & 1/20 dil.3 & 326,100 & 75,956 & 4.29 & 720.03 & 14.40 & & \\
\hline \multirow[t]{3}{*}{ Liquiritigenin (LG) } & 1/20 dil.1 & 153,592 & 74,555 & 2.06 & 65.84 & 1.32 & 1.34 & 0.02 \\
\hline & 1/20 dil.2 & 154,374 & 73,402 & 2.10 & 67.33 & 1.35 & & \\
\hline & 1/20 dil.3 & 159,391 & 75,956 & 2.10 & 67.16 & 1.34 & & \\
\hline
\end{tabular}

A



\section{Alcohol}

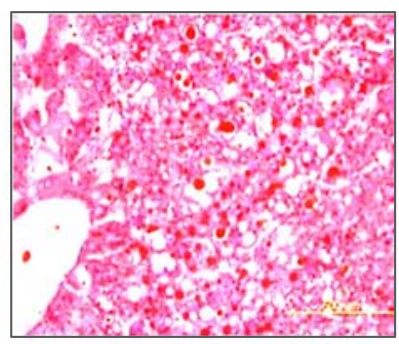

Alochol $+25 \mathrm{mg} / \mathrm{kg}$

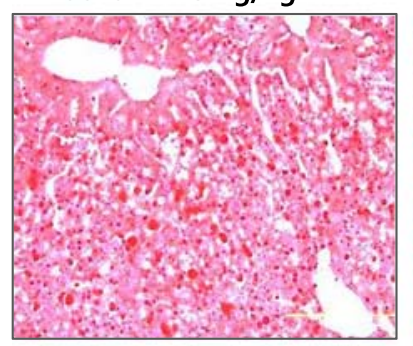

\section{Alochol $+50 \mathrm{mg} / \mathrm{kg}$}

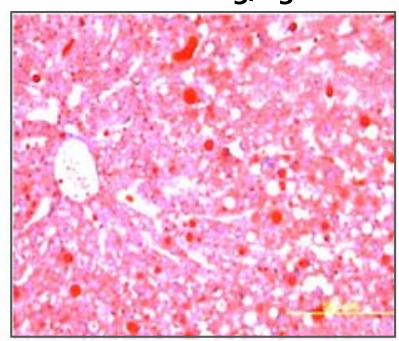

Alochol $+100 \mathrm{mg} / \mathrm{kg}$

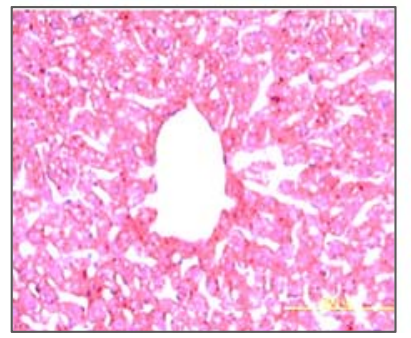

Alochol $+200 \mathrm{mg} / \mathrm{kg}$

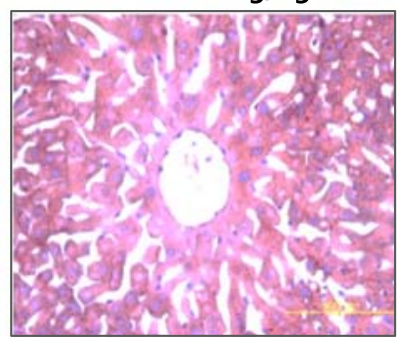

B

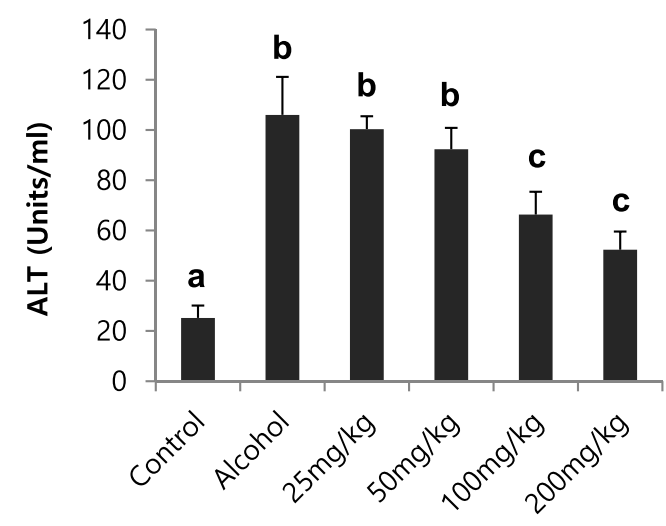

C

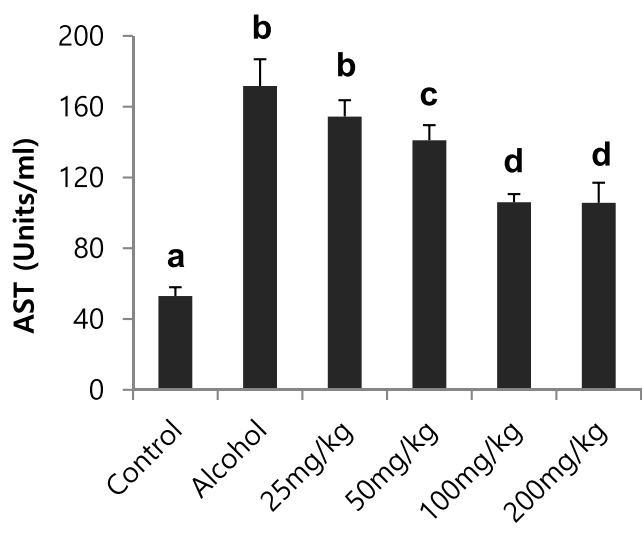

Fig. 4 Dose-dependence study of licorice in alcohol-induced fatty liver. Hepatic lipid accumulation (a), serum ALT (b) and AST (c) activities in mice fed different diet with or without licorice. The livers were stained with Oil red O for histopathological examination. Each value represents the mean \pm SD for 6 mice. Values with different letters are significantly different from one another (ANOVA followed by Newman-Keuls multiple range test $P<0.05)$ 


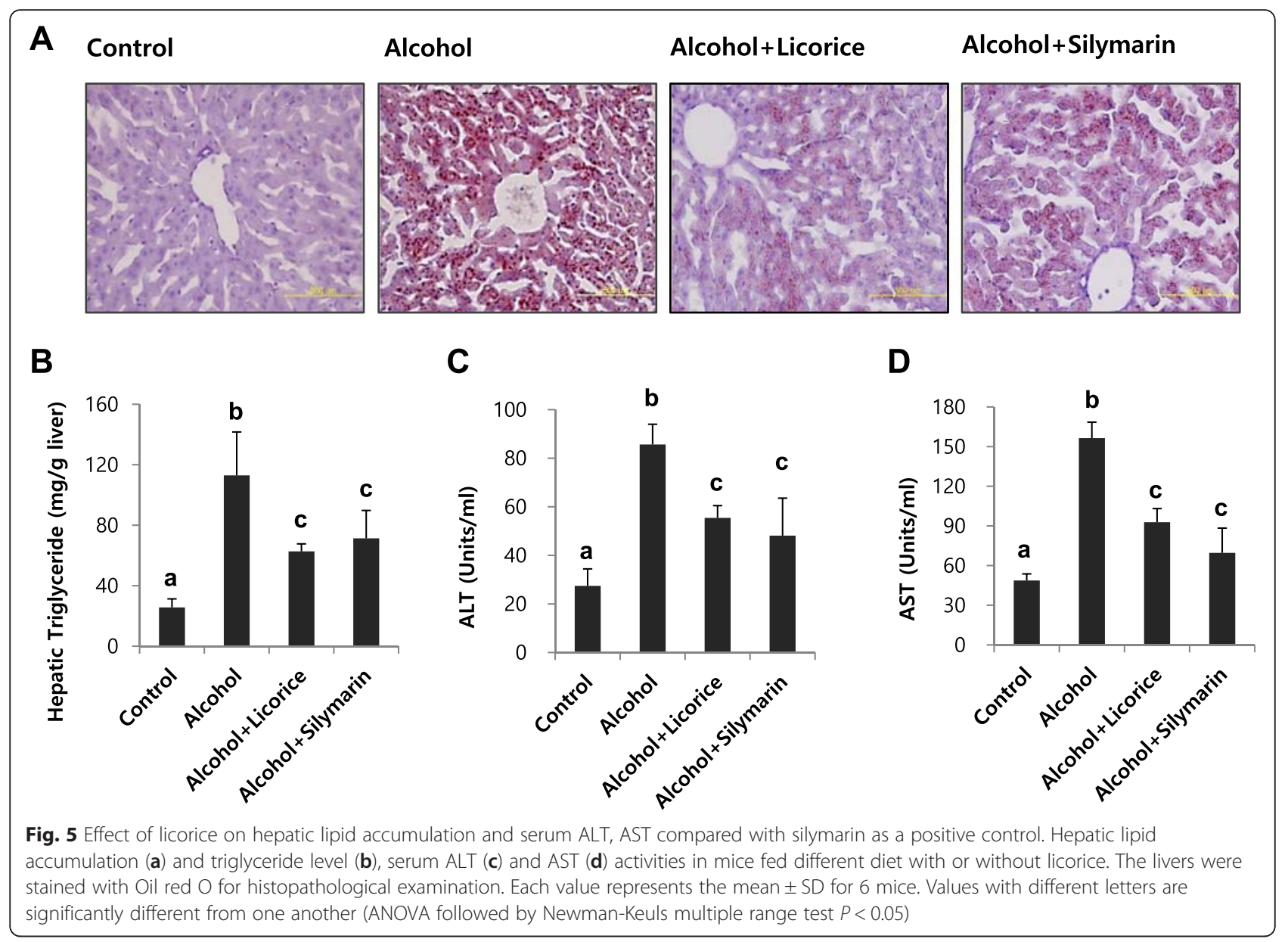

that licorice was a promising candidate to alleviate alcoholic fatty liver in comparison with the inhibitory effect of silymarin on fat accumulation induced by chronic alcohol ingestion (Fig. 5a and b).

Biochemical analyses of serum ALT, AST activities, and liver triglyceride levels corresponded to the histopathologic findings: licorice administration significantly attenuated the effects of ethanol on triglyceride accumulation in the liver and ALT and AST activities in serum (Fig. $5 \mathrm{c}$ and d). The hepatic GSH content in ethanol-treated mice was significantly lower than that in the control mice. Licorice treatment restored GSH to its original level (Fig. 6a). Licorice also significantly decreased the level of serum TNF- $\alpha$ (Fig. 6b).

To find detailed mechanism for the hepatic lipid lowering effect of licorice, we analyzed the hepatic expression levels of the lipogenic genes such as Srebf1 and Fasn, and the genes involved in lipid transportation such as Mttp, Apob, Cd36, Lpl, Ldlr, Fatp1, Fatp2, Fatp3, Fatp4, and Fatp5 (Fig. 7). Chronic alcohol drinking significantly enhanced Srebf1 expression and the mRNA level of Cd36 and Lpl, Fatp4 related to lipid uptake. However, licorice supplement significantly prevented the induction of these genes expression.

\section{Discussion}

Although the mechanisms of the induction of fatty liver by alcohol appear to be complicated, accumulating lines of evidence suggest contribution of both oxidative stress and inflammation. On the basis of our recent findings that licorice protects cells against inflammation and oxidative stress [16], we hypothesized that licorice would alleviate alcohol-induced fatty liver injury.

In mice fed a standard Lieber-DeCarli alcohol diet for 4 weeks, hepatic triglyceride levels increased and GSH content decreased with concomitant increases in serum ALT and AST activities, triglycerides, and TNF- $\alpha$. Supplementation of the alcohol diet with licorice for the same time period significantly reversed the changes in liver injury markers and effectively abrogated fat accumulation. Thus, we suggest that the hepatoprotective 
A

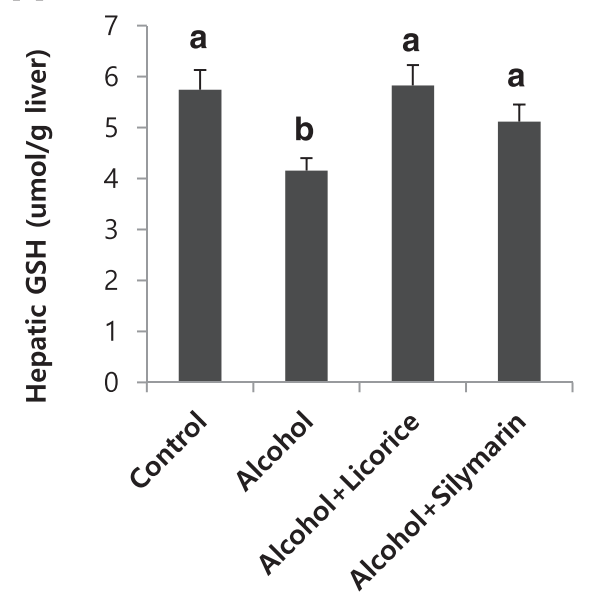

B

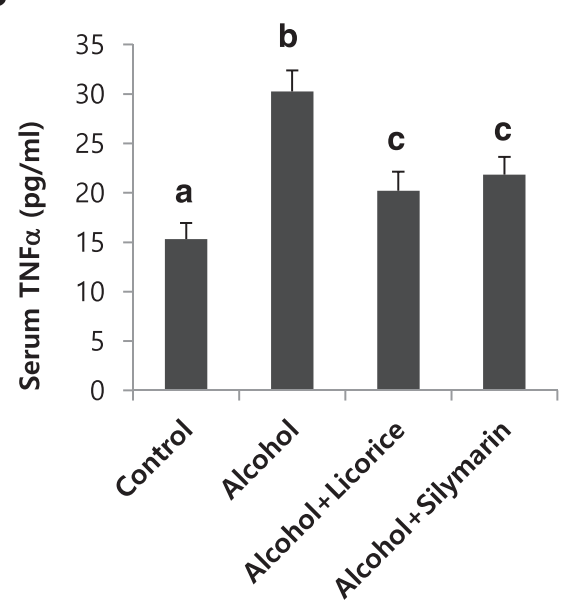

Fig. 6 Effect of licorice on the level of hepatic GSH (a) and serum TNFa (b) in alcohol-induced fatty liver. Each value represents the mean \pm SD for 6 mice. Values with different letters are significantly different from one another (ANOVA followed by Newman-Keuls multiple range test $P<0.05$ )

A

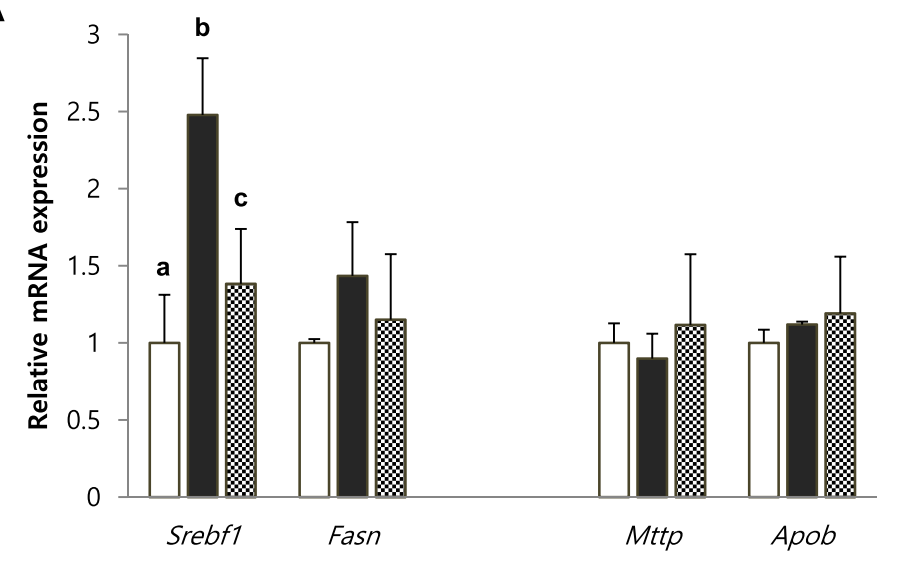

B

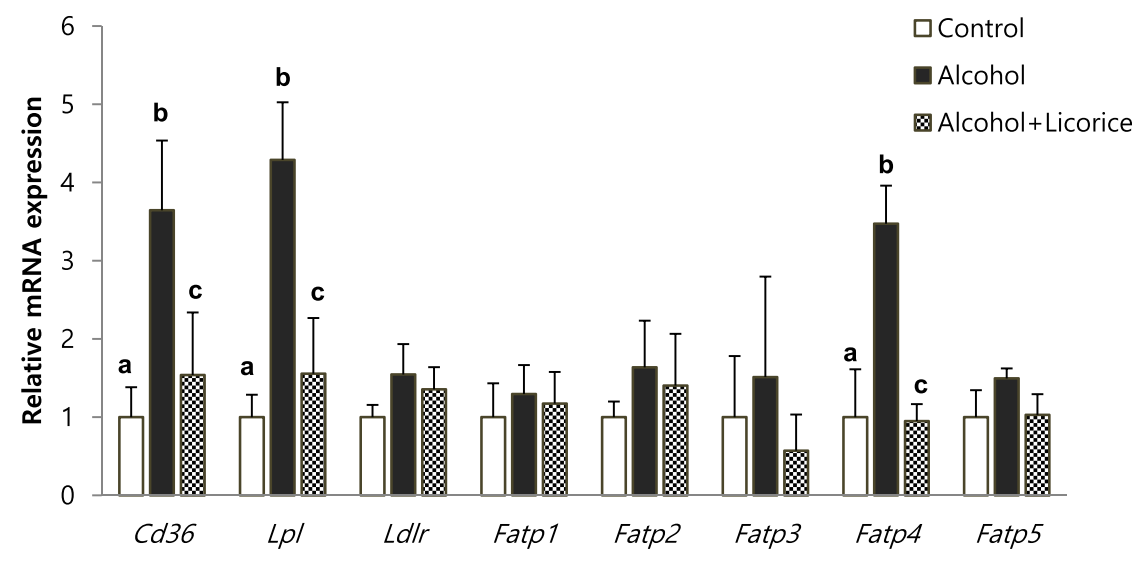

Fig. 7 Effect of licorice on the level of hepatic mRNA expression in alcohol-induced fatty liver. mRNA expression of Srebf1 and Fasn for lipogenesis, and Mttp and Apob for lipid export in the liver (a). Expression of mRNA related to lipid uptake in the liver (b). Each value represents the mean \pm SD for 6 mice. Values with different letters are significantly different from one another (ANOVA followed by Newman-Keuls multiple range test $P<0.05$ ) 
effect of licorice is associated with an augmentation of antioxidant defense and anti-inflammatory response.

$\mathrm{GSH}$, a thiol-containing tripeptide, plays a major antioxidant and detoxification role in the liver. Alcohol increases the levels of intracellular reactive oxygen species and depletes mitochondrial GSH, and therefore induces oxidative stress [18]. Although the contribution of oxidative injury to the development of alcoholic fatty liver remains to be elucidated, enhancement of antioxidant capacity using some compounds ameliorates alcoholic fatty liver [19-22]. In line with these results, overexpression of superoxide dismutase prevents the accumulation of lipid droplets in hepatocytes, whereas double knockout of glutathione peroxidase- 1 and catalase aggravates alcohol-induced liver injury [23-25]. Our results thus indicate that an improvement in the antioxidant capacity in alcohol-fed mice via recovery of the hepatic GSH pool could make licorice valuable in the treatment of alcoholic liver disease.

Direct inflammatory and cytotoxic effects of TNF- $\alpha$ in alcoholic liver disease are well characterized. Chronic drinking of alcohol increases the level of bacterial endotoxin, which stimulates resident liver macrophages to produce free radicals and cytokines [26]. NADPH oxidase plays critical roles in the generation of oxidants in resident liver macrophages after alcohol intake. Activation of NF-kB by oxidant generation leads to an increase in the TNF- $\alpha$ level, which causes tissue injury [27]. Moreover, TNF- $\alpha$ is suggested to induce lipolysis in adipose tissue followed eventually by fatty liver. Earlier studies showed that TNF- $\alpha$ causes free fatty acid release from adipocytes, stimulates lipogenesis in the liver, and inhibits $\beta$-oxidation of free fatty acids [28-30]. Moreover, in a more recent report, TNF- $\alpha$ was suggested to increase intrahepatic fat deposition by affecting hepatic lipogenic metabolism that involves SREBP-1c [31]. Indeed, TNFR1 knockout almost completely blocks the development of alcohol-induced fatty liver [32] . In agreement with these reports, the present study demonstrated that licorice significantly inhibited up-regulation of Srebf 1 by chronic alcohol drinking. Importantly, increase of gene expression involved in lipid uptake such as $C d 36, L p l$, and Fatp 4 is also effectively reduced by licorice treatment. Considering the importance of TNF- $\alpha$ in the development of alcoholic fatty liver, suppression of TNF- $\alpha$ secretion by licorice may contribute to its overall preventive effect in alcoholic liver injury.

\section{Conclusion}

We found that licorice is effective in preventing alcoholic fatty liver in mice. An important issue in the management of alcoholic liver disease is the progression of simple fat accumulation to alcoholic hepatitis. Licorice treatment restored hepatic GSH content and inhibited TNF- $\alpha$ secretion, and also inhibited lipid accumulation in the liver of chronic alcohol-fed mice. Therefore, licorice is a promising candidate to prevent the progression of alcoholic liver injury, which probably acts by enhancing anti-oxidative and anti-inflammatory capacity.

\section{Additional file}

Additional file 1: Table S1. List of murine primers used for real time RT-PCR. (DOCX $17 \mathrm{~kb}$ )

\section{Competing interests}

The authors declare that there is no conflict of interests regarding the publication of this paper.

\section{Authors' contributions}

$J C J, Y H L$, and YSJ designed the study and prepared the manuscript. JCJ, YHL, SHK, KJK, KMK, and SO carried out experiment. All authors have read and approved the final version of this manuscript.

\section{Acknowledgements}

This research was supported by the Basic Science Research Program through the National Research Foundation of Korea (NRF) funded by the Ministry of Science, ICT\&Future Planning (NRF-2014R1A1A1005435). This research was also financially supported by the Ministry of Trade, Industry and Energy (MOTIE) and the Korea Institute for Advancement of Technology (KIAT) through Promoting Regional Specialized Industry (R0002317).

\section{Author details}

'Life Science Research Institute, Novarex Co., Ltd, Ochang, Cheongwon, Chungbuk 363-885, Republic of Korea. ${ }^{2}$ College of Pharmacy, Yonsei University, Incheon 406-840, Republic of Korea. ${ }^{3}$ College of Pharmacy, Pusan National University, Busan 609-735, Republic of Korea. ${ }^{4}$ Department of Biomedical Laboratory Science, Daekyeung College, Gyeongsan 712-719, Republic of Korea. ${ }^{5}$ Department of Molecular Medicine and Tissue Injury Defense Research Center, School of Medicine, Ewha Woman's University, Seoul 158-710, Republic of Korea.

Received: 20 September 2015 Accepted: 12 January 2016 $\mathrm{HP}$ (?)

References

1. Wang X, Zhang H, Chen L, Shan L, Fan G, Gao X. Liquorice, a unique "guide drug" of traditional Chinese medicine: a review of its role in drug interactions. J Ethnopharmacol. 2013;150(3):781-90.

2. Cantelli-Forti G, Maffei F, Hrelia P, Bugamelli F, Bernardi M, D'Intino P, et al. Interaction of licorice on glycyrrhizin pharmacokinetics. Environ Health Perspect. 1994;102 Suppl 9:65-8.

3. Li HY, Xu W, Su J, Zhang X, Hu LW, Zhang WD. In vitro and in vivo inhibitory effects of glycyrrhetinic acid on cytochrome P450 3A activity. Pharmacology. 2010;86(5-6):287-92.

4. Liao WC, Lin YH, Chang TM, Huang WY. Identification of two licorice species, Glycyrrhiza uralensis and Glycyrrhiza glabra, based on separation and identification of their bioactive components. Food Chem. 2012;132(4):2188-93.

5. Montoro P, Maldini M, Russo M, Postorino S, Piacente S, Pizza C. Metabolic profiling of roots of liquorice (Glycyrrhiza glabra) from different geographical areas by ESI/MS/MS and determination of major metabolites by LC-ESI/MS and LC-ESI/MS/MS. J Pharm Biomed Anal. 2011;54(3):535-44.

6. Farag MA, Porzel A, Wessjohann LA. Comparative metabolite profiling and fingerprinting of medicinal licorice roots using a multiplex approach of GCMS, LC-MS and 1D NMR techniques. Phytochemistry. 2012;76:60-72.

7. Fu Y, Chen J, Li YJ, Zheng YF, Li P. Antioxidant and anti-inflammatory activities of six flavonoids separated from licorice. Food Chem. 2013;141(2):1063-71.

8. Gafner S, Bergeron C, Villinski JR, Godejohann M, Kessler P, Cardellina JH, et al. Isoflavonoids and coumarins from Glycyrrhiza uralensis: antibacterial activity against oral pathogens and conversion of isoflavans into isoflavanquinones during purification. J Nat Prod. 2011;74(12):2514-9. 
9. Chung WT, Lee SH, Kim JD, Sung NS, Hwang B, Lee SY, et al. Effect of the extracts from Glycyrrhiza uralensis Fisch on the growth characteristics of human cell lines: Anti-tumor and immune activation activities. Cytotechnology. 2001;37(1):55-64.

10. Chen HJ, Kang SP, Lee IJ, Lin YL. Glycyrrhetinic acid suppressed NF-kappaB activation in TNF-alpha-induced hepatocytes. J Agric Food Chem. 2014; 62(3):618-25.

11. Huo HZ, Wang B, Liang YK, Bao YY, Gu Y. Hepatoprotective and antioxidant effects of licorice extract against $\mathrm{CCl}(4)$-induced oxidative damage in rats. Int J Mol Sci. 2011;12(10):6529-43.

12. Jeong HG, You HJ, Park SJ, Moon AR, Chung YC, Kang SK, et al. Hepatoprotective effects of 18beta-glycyrrhetinic acid on carbon tetrachloride-induced liver injury: inhibition of cytochrome P450 2E1 expression. Pharmacol Res. 2002;46(3):221-7.

13. Teli MR, Day CP, Burt AD, Bennett MK, James OF. Determinants of progression to cirrhosis or fibrosis in pure alcoholic fatty liver. Lancet. 1995; 346(8981):987-90.

14. Deleuran T, Gronbaek H, Vilstrup H, Jepsen P. Cirrhosis and mortality risks of biopsy-verified alcoholic pure steatosis and steatohepatitis: a nationwide registry-based study. Aliment Pharmacol Ther. 2012;35(11):1336-42.

15. Haflidadottir S, Jonasson JG, Norland H, Einarsdottir SO, Kleiner DE, Lund SH, et al. Long-term follow-up and liver-related death rate in patients with non-alcoholic and alcoholic related fatty liver disease. BMC Gastroenterol. 2014;14:166.

16. Yu JY, Ha JY, Kim KM, Jung YS, Jung JC, Oh S. Anti-Inflammatory Activities of Licorice Extract and Its Active Compounds, Glycyrrhizic Acid, Liquiritin and Liquiritigenin, in BV2 Cells and Mice Liver. Molecules. 2015;20(7):13041-54.

17. Neuschwander-Tetri BA, Roll FJ. Glutathione measurement by high-performance liquid chromatography separation and fluorometric detection of the glutathione-orthophthalaldehyde adduct. Anal Biochem. 1989;179(2):236-41.

18. Fernandez-Checa JC, Kaplowitz N, Garcia-Ruiz C, Colell A, Miranda M, Mari M, et al. GSH transport in mitochondria: defense against TNF-induced oxidative stress and alcohol-induced defect. Am J Physiol. 1997;273(1 Pt 1):G7-17.

19. Kono H, Rusyn I, Bradford BU, Connor HD, Mason RP, Thurman RG. Allopurinol prevents early alcohol-induced liver injury in rats. J Pharmacol Exp Ther. 2000;293(1):296-303.

20. Kono H, Arteel GE, Rusyn I, Sies H, Thurman RG. Ebselen prevents early alcohol-induced liver injury in rats. Free Radic Biol Med. 2001;30(4):403-11.

21. Kono H, Rusyn I, Uesugi T, Yamashina S, Connor HD, Dikalova A, et al. Diphenyleneiodonium sulfate, an NADPH oxidase inhibitor, prevents early alcohol-induced liver injury in the rat. Am J Physiol Gastrointest Liver Physiol. 2001;280(5):G1005-1012.

22. McKim SE, Konno A, Gabele E, Uesugi T, Froh M, Sies H, et al. Cocoa extract protects against early alcohol-induced liver injury in the rat. Arch Biochem Biophys. 2002;406(1):40-6.

23. Wheeler MD, Kono H, Yin M, Rusyn I, Froh M, Connor HD, et al. Delivery of the $\mathrm{Cu} / \mathrm{Zn}$-superoxide dismutase gene with adenovirus reduces early alcohol-induced liver injury in rats. Gastroenterology. 2001;120(5):1241-50.

24. Wheeler MD, Nakagami M, Bradford BU, Uesugi T, Mason RP, Connor HD, et al. Overexpression of manganese superoxide dismutase prevents alcoholinduced liver injury in the rat. J Biol Chem. 2001;276(39):36664-72.

25. Kim SJ, Lee JW, Jung YS, Kwon do Y, Park HK, Ryu CS, et al. Ethanol-induced liver injury and changes in sulfur amino acid metabolomics in glutathione peroxidase and catalase double knockout mice. J Hepatol. 2009;50(6):1184-91.

26. Bode C, Bode JC. Activation of the innate immune system and alcoholic liver disease: effects of ethanol per se or enhanced intestinal translocation of bacterial toxins induced by ethanol? Alcohol Clin Exp Res. 2005;29(11 Suppl):166S-71S.

27. Arteel GE. Oxidants and antioxidants in alcohol-induced liver disease. Gastroenterology. 2003;124(3):778-90.

28. Feingold KR, Grunfeld C. Tumor necrosis factor-alpha stimulates hepatic lipogenesis in the rat in vivo. J Clin Invest. 1987;80(1):184-90.

29. Hardardottir I, Doerrler W, Feingold KR, Grunfeld C. Cytokines stimulate lipolysis and decrease lipoprotein lipase activity in cultured fat cells by a prostaglandin independent mechanism. Biochem Biophys Res Commun. 1992;186(1):237-43.

30. Nachiappan V, Curtiss D, Corkey BE, Kilpatrick L. Cytokines inhibit fatty acid oxidation in isolated rat hepatocytes: synergy among TNF, IL-6, and IL-1. Shock. 1994;1(2):123-9.
31. Endo M, Masaki T, Seike M, Yoshimatsu H. TNF-alpha induces hepatic steatosis in mice by enhancing gene expression of sterol regulatory element binding protein-1c (SREBP-1c). Exp Biol Med. 2007;232(5):614-21.

32. Yin M, Wheeler MD, Kono H, Bradford BU, Gallucci RM, Luster Ml, et al. Essential role of tumor necrosis factor alpha in alcohol-induced liver injury in mice. Gastroenterology. 1999;117(4):942-52.

\section{Submit your next manuscript to BioMed Central and we will help you at every step:}

- We accept pre-submission inquiries

- Our selector tool helps you to find the most relevant journal

- We provide round the clock customer support

- Convenient online submission

- Thorough peer review

- Inclusion in PubMed and all major indexing services

- Maximum visibility for your research

Submit your manuscript at www.biomedcentral.com/submit
Biomed Central 